\title{
Gasoline-Equivalent Gallon
}

National Cancer Institute

\section{Source}

National Cancer Institute. Gasoline-Equivalent Gallon. NCI Thesaurus. Code C69097.

A unit used to compare the energy content of gasoline and alternative energy sources

equal to approximately 33.705 watt-hours. 